Supplement of Atmos. Chem. Phys., 16, 9533-9548, 2016

http://www.atmos-chem-phys.net/16/9533/2016/

doi:10.5194/acp-16-9533-2016-supplement

(C) Author(s) 2016. CC Attribution 3.0 License.

(c) (i)

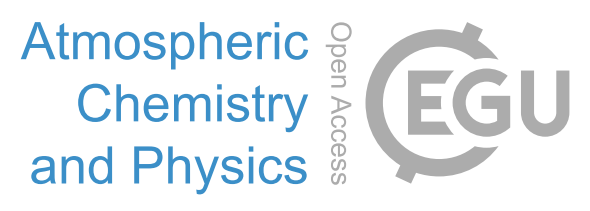

Supplement of

\title{
Co-benefits of global and regional greenhouse gas mitigation for US air quality in 2050
}

Yuqiang Zhang et al.

Correspondence to: J. Jason West (jjwest@email.unc.edu)

The copyright of individual parts of the supplement might differ from the CC-BY 3.0 licence. 


\section{SUPPLEMENTAL MATERIAL}

Median Bias: $M d n B=\operatorname{median}\left(C_{m}-C_{o}\right)_{N}$

Normalized Median Bias: $N M d n B=\frac{\operatorname{median}\left(C_{m}-C_{o}\right)_{N}}{\text { median }\left(C_{o}\right)_{N}} \times 100 \%$

Median Error: $M d n E=$ median $\left|C_{m}-C_{o}\right|_{N}$

Normalized Median Error: $N M d n E=\frac{\text { median }\left|C_{m}-C_{o}\right|_{N}}{\operatorname{median}\left(C_{o}\right)_{N}} \times 100 \%$

Table S1. Sectors grouped in RCPs, SCC in the GSREF file, and the speciation profile codes in GSPRO used in SMOKE v3.5. $\mathrm{X}$ in the table represents any number.

\begin{tabular}{lrrr}
\hline Sectors & IPCC Code & SCC & $\begin{array}{r}\text { Speciation profile } \\
\text { codes }\end{array}$ \\
\hline Energy & 1A1_1B & 10100XXXX & 92036 \\
Industries & 1A2_2A_B_C_D_E & 10200XXXX & 92084 \\
Transportation & 1A3b_c_e & 220100XXXX & 92050 \\
Residential & 1A4 & 21040080XX & 92068 \\
Solvents & 2F_3 & 24XXXXXXX & 92052 \\
Agriculture & 4A_B_C_D_G & 27301000XX & 92001 \\
Agriculture waste & 4F & 2610000XXX & 92000 \\
burning & & & \\
Waste & & & 92082 \\
Savanna burning & 6A_B_C_D & $101012 X X$ & 92090 \\
Forest fires & 4E & 28100010XX & 92090 \\
\hline
\end{tabular}


Table S2. Evaluation of the S_2000 simulation (average of three years modeled) with surface observations in 2000 for $\mathrm{PM}_{2.5}$ components $\left(\mathrm{SO}_{4}{ }^{2-}, \mathrm{NO}_{3}{ }^{-}, \mathrm{NH}_{4}{ }^{+}\right.$, OC and $\left.\mathrm{EC}\right)$ with different networks $\left(\mu \mathrm{g} \mathrm{m}^{-3}\right)$.

\begin{tabular}{lrrrrr}
\hline & Pollutant & MdnB & NMdnB (\%) & MdnE & NMdnE(\%) \\
\hline IMPROVE & $\mathrm{SO}_{4}{ }^{2-}$ & 0.16 & 20.75 & 0.45 & 56.96 \\
IMPROVE & $\mathrm{NO}_{3}{ }^{-}$ & -0.040 & -18.14 & 0.23 & 83.91 \\
IMPROVE & $\mathrm{OC}$ & -0.55 & -63.55 & 0.60 & 69.13 \\
IMPROVE & $\mathrm{EC}$ & -0.069 & -37.00 & 0.11 & 57.04 \\
CSN & $\mathrm{SO}_{4}{ }^{2-}$ & -0.10 & -4.88 & 0.91 & 44.32 \\
CSN & $\mathrm{NO}_{3}{ }^{-}$ & -0.31 & -50.06 & 0.44 & 71.39 \\
CSN & $\mathrm{NH}_{3}{ }^{+}$ & 0.029 & 4.27 & 0.43 & 64.67 \\
CASTNET & $\mathrm{SO}_{4}{ }^{-}$ & -0.40 & -15.2 & 0.73 & 27.87 \\
CASTNET & $\mathrm{NO}_{3}{ }^{-}$ & -0.051 & -10.50 & 0.37 & 74.97 \\
CASTNET & $\mathrm{NH}_{4}{ }^{+}$ & -0.076 & -7.63 & 0.31 & 31.30 \\
\hline
\end{tabular}


Table S3. The regional annual means of total, domestic, and foreign co-benefits for $\mathrm{PM}_{2.5}$ and $\mathrm{O}_{3}$ in the nine U.S. regions. The values (mean \pm coefficient of variation $(\mathrm{CV}, \%)$ ) are calculated over three years.

\begin{tabular}{lccc|ccc}
\hline & \multicolumn{2}{c}{ Annual PM $2.5\left(\boldsymbol{\mu} \mathbf{~ m}^{-3}\right)$} & \multicolumn{3}{c}{$\begin{array}{l}\text { Ozone season (May-Oct) average of } \\
\text { MDA8 O3 (ppbv) }\end{array}$} \\
\cline { 2 - 7 } & Total & Domestic & Foreign & Total & Domestic & Foreign \\
U.S. & $-0.47 \pm 7$ & $-0.35 \pm 1$ & $-0.12 \pm 26$ & $-3.55 \pm 37$ & $-0.86 \pm 1$ & $-2.69 \pm 49$ \\
Northwest & $-0.16 \pm 15$ & $-0.13 \pm 2$ & $-0.04 \pm 66$ & $-4.15 \pm 21$ & $-0.40 \pm 5$ & $-3.75 \pm 28$ \\
West & $-0.40 \pm 9$ & $-0.30 \pm 3$ & $-0.10 \pm 45$ & $-3.99 \pm 46$ & $-1.05 \pm 3$ & $-2.94 \pm 61$ \\
West N. Central & $-0.21 \pm 14$ & $-0.13 \pm 3$ & $-0.08 \pm 38$ & $-4.02 \pm 41$ & $-0.57 \pm 3$ & $-3.45 \pm 48$ \\
Southwest & $-0.30 \pm 12$ & $-0.16 \pm 1$ & $-0.13 \pm 24$ & $-3.11 \pm 70$ & $-0.79 \pm 3$ & $-2.32 \pm 93$ \\
South & $-0.62 \pm 11$ & $-0.37 \pm 4$ & $-0.25 \pm 22$ & $-2.84 \pm 69$ & $-0.79 \pm 3$ & $-2.04 \pm 95$ \\
East N. Central & $-0.45 \pm 3$ & $-0.38 \pm 3$ & $-0.06 \pm 29$ & $-4.25 \pm 30$ & $-0.81 \pm 4$ & $-3.44 \pm 37$ \\
Central & $-0.78 \pm 9$ & $-0.65 \pm 2$ & $-0.12 \pm 63$ & $-3.38 \pm 55$ & $-1.24 \pm 1$ & $-2.14 \pm 87$ \\
Southeast & $-0.75 \pm 29$ & $-0.62 \pm 3$ & $-0.13 \pm 84$ & $-2.67 \pm 40$ & $-1.14 \pm 3$ & $-1.53 \pm 71$ \\
Northeast & $-0.62 \pm 3$ & $-0.53 \pm 1$ & $-0.09 \pm 22$ & $-4.61 \pm 17$ & $-1.16 \pm 5$ & $-3.45 \pm 21$ \\
\hline
\end{tabular}



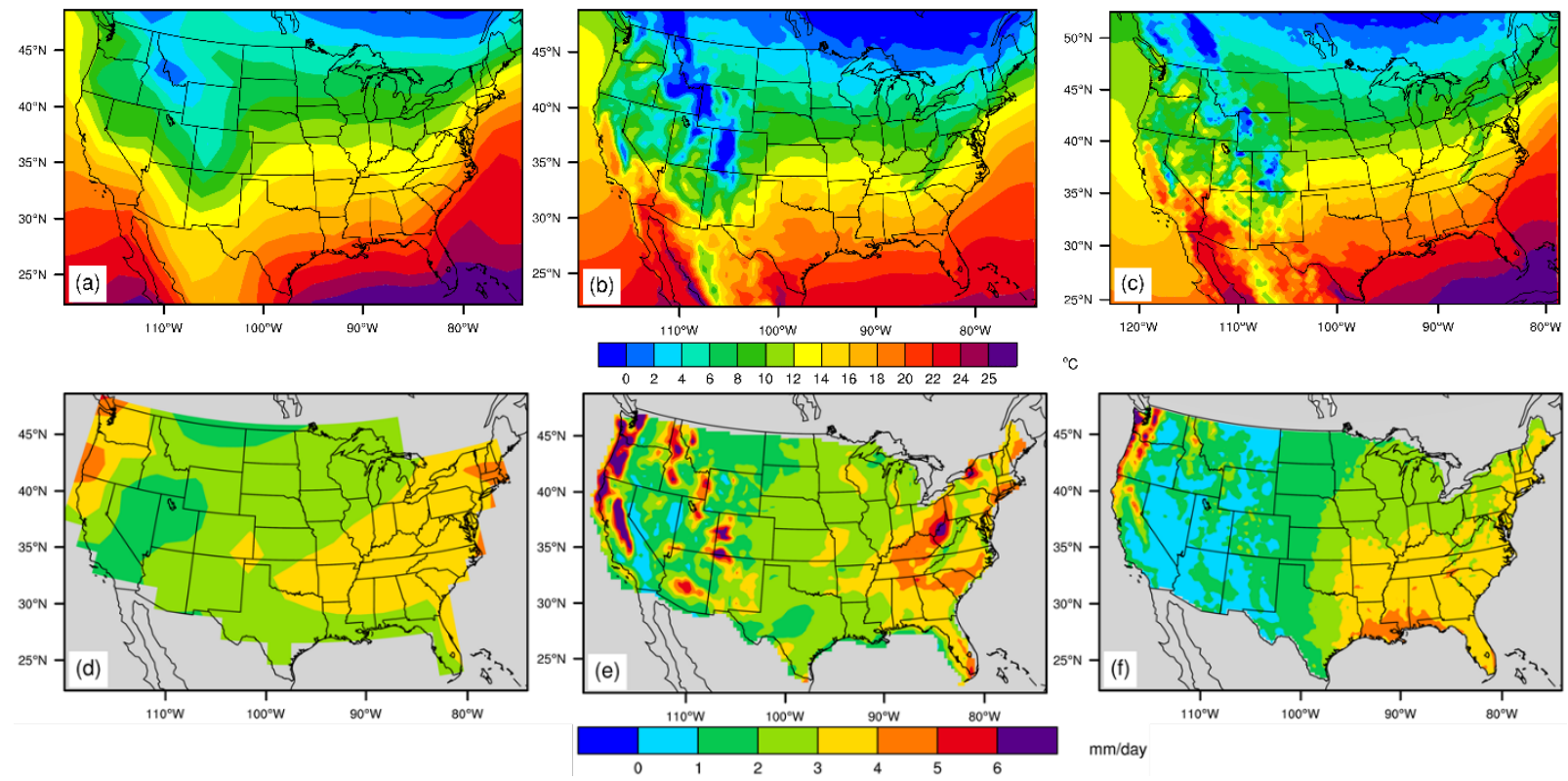

${ }^{\circ} \mathrm{C}$

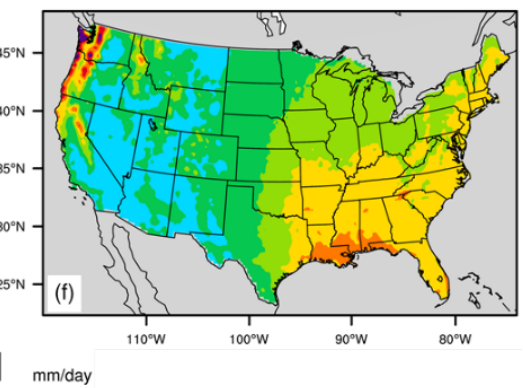

Figure S1. Comparisons of the annual average 2-m temperature (a, b, c) and precipitation (d, e, f) in 2000, for GFDL AM3 (a, d, three-year average), WRF (b, e, three-year average) and 2-m temperature from the North American Regional Reanalysis (c, long-term mean from 1979 2000), and Unified US precipitation from the NOAA Climate Prediction Center (f, long-term mean from 1948-1998). 

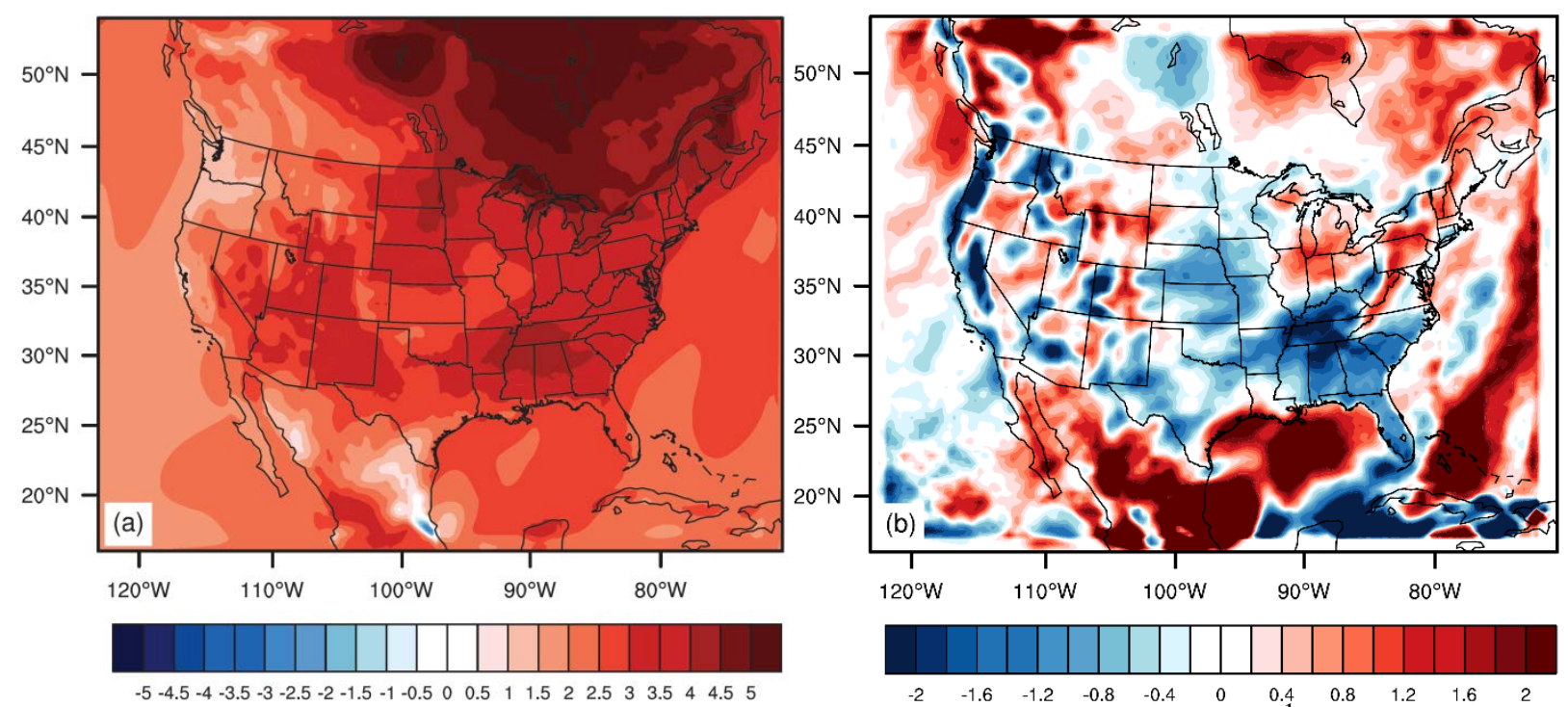

Figure S2. Changes in (a) 2-m temperature $\left({ }^{\circ} \mathrm{C}\right.$ ) and (b) precipitation $\left(\mathrm{mm}^{-1 a y}{ }^{-1}\right)$ centered on 2050 from RCP8.5 and 2000 (2050—2000).
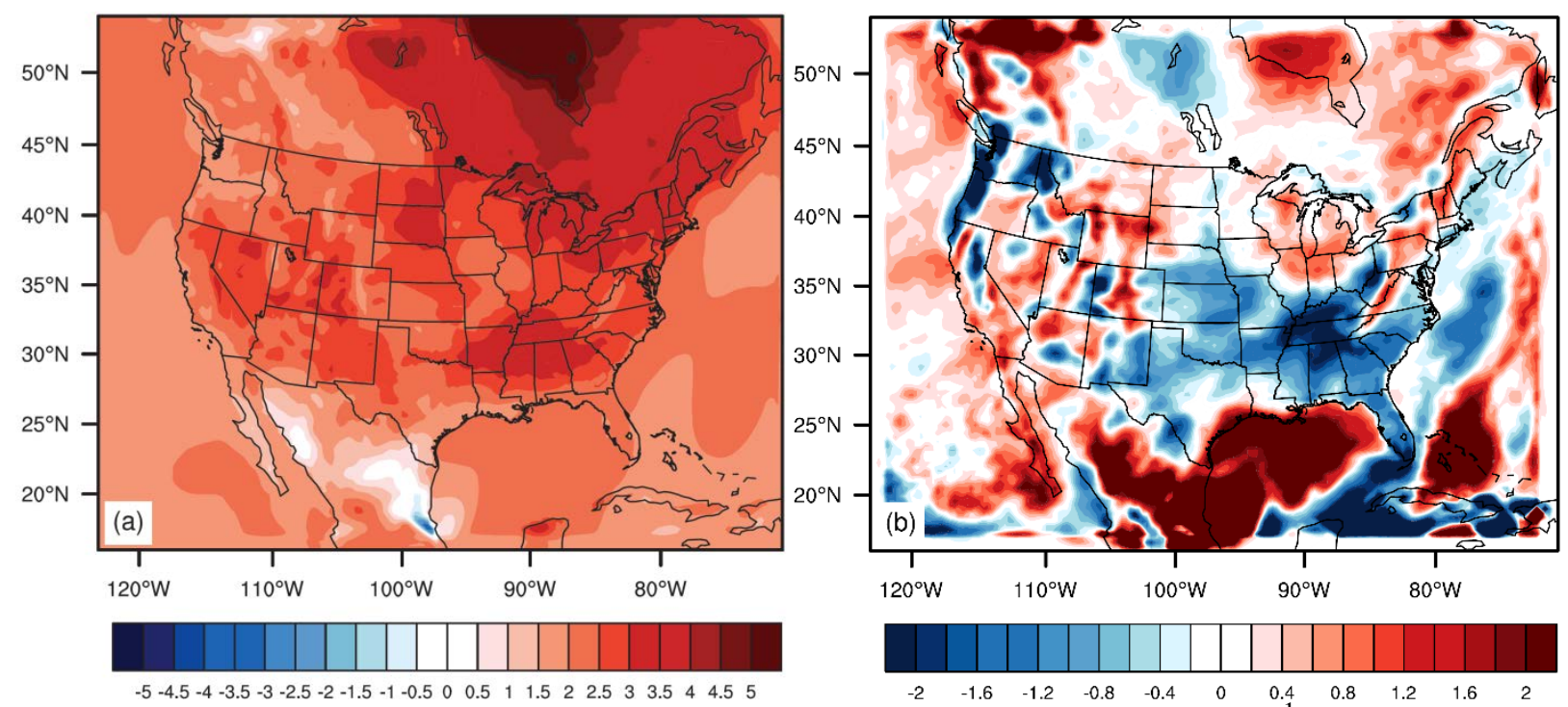

Figure S3. Changes in (a) 2-m temperature $\left({ }^{\circ} \mathrm{C}\right.$ ) and (b) precipitation (mm day ${ }^{-1}$ ) centered on 2050 from RCP4.5 and 2000 (2050—2000). 

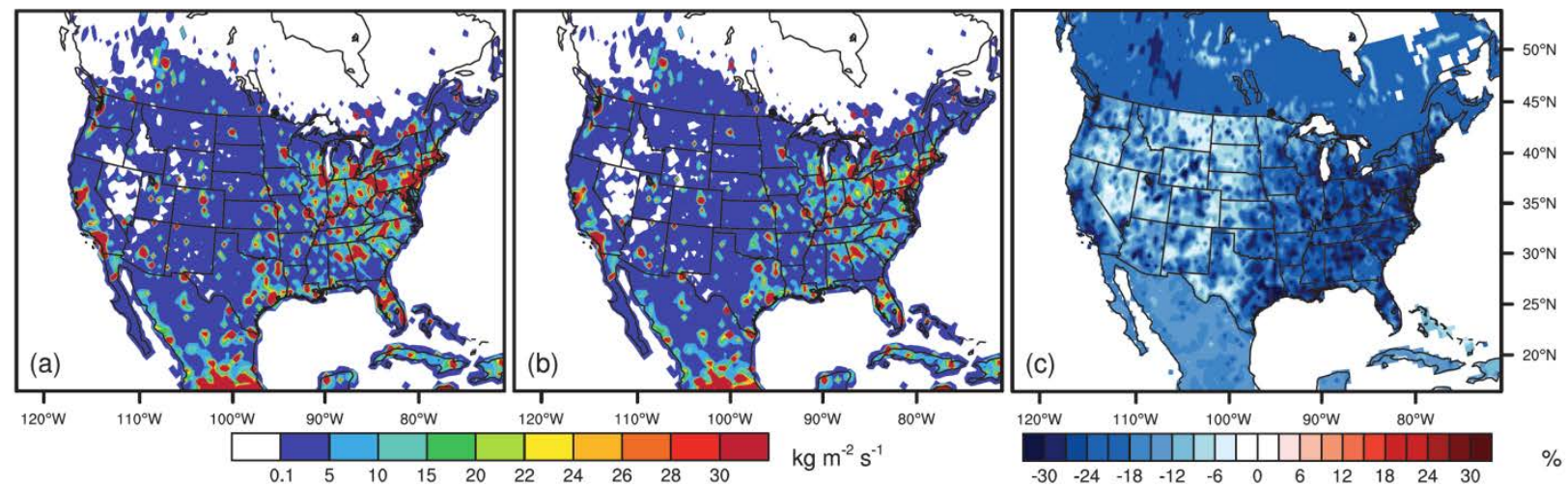

Figure S4. The spatial distribution of anthropogenic emissions of $\mathrm{SO}_{2}\left(10^{-12} \mathrm{~kg} \mathrm{~m}^{-2} \mathrm{~s}^{-1}\right)$ from (a) REF scenario, (b) RCP45 scenario in 2050, and (c) relative differences between these two scenarios (RCP45-REF)/REF×100\%).
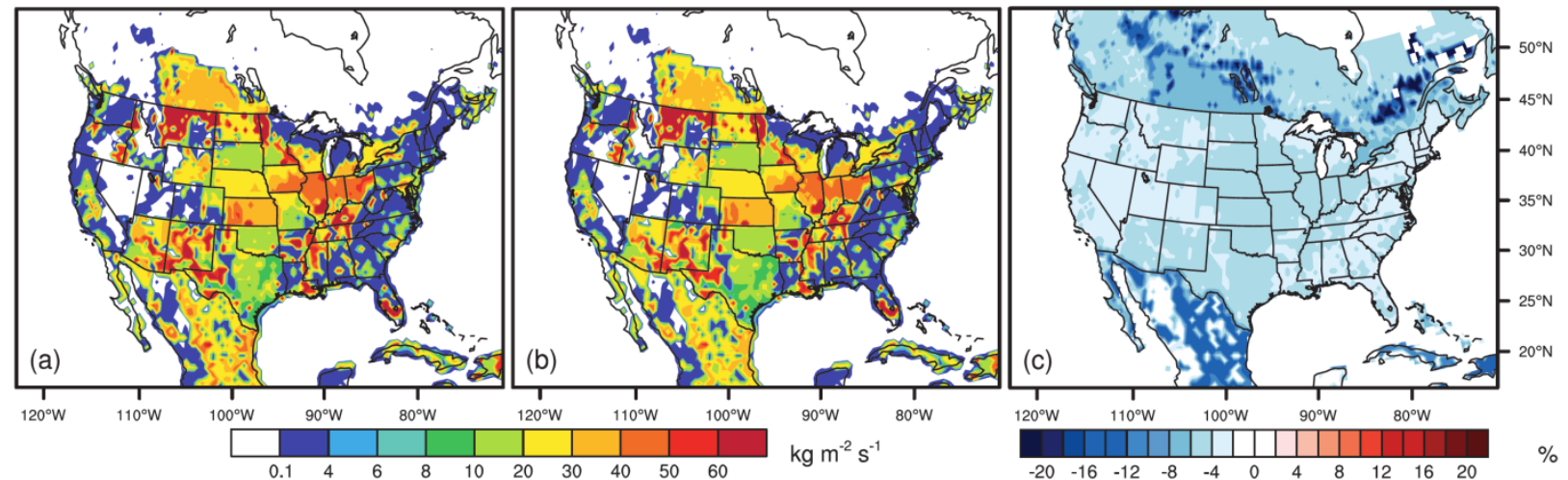

Figure S5. Same as Fig. S4 but for $\mathrm{NH}_{3}$.
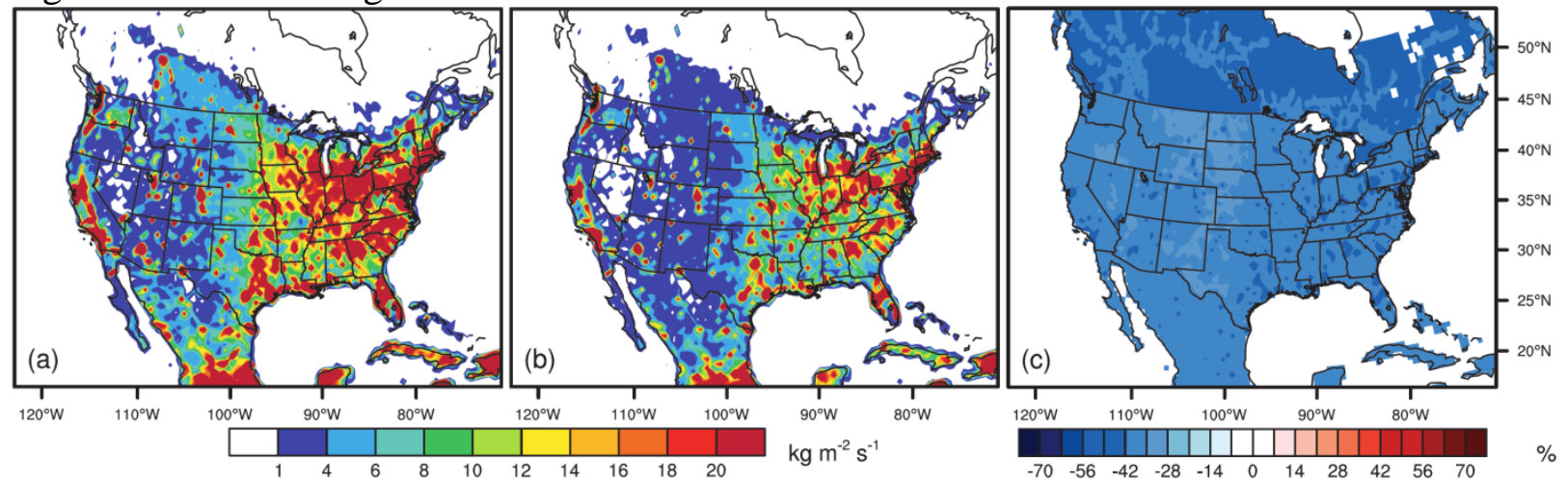

Figure S6. Same as Fig. S4 but for NO. 

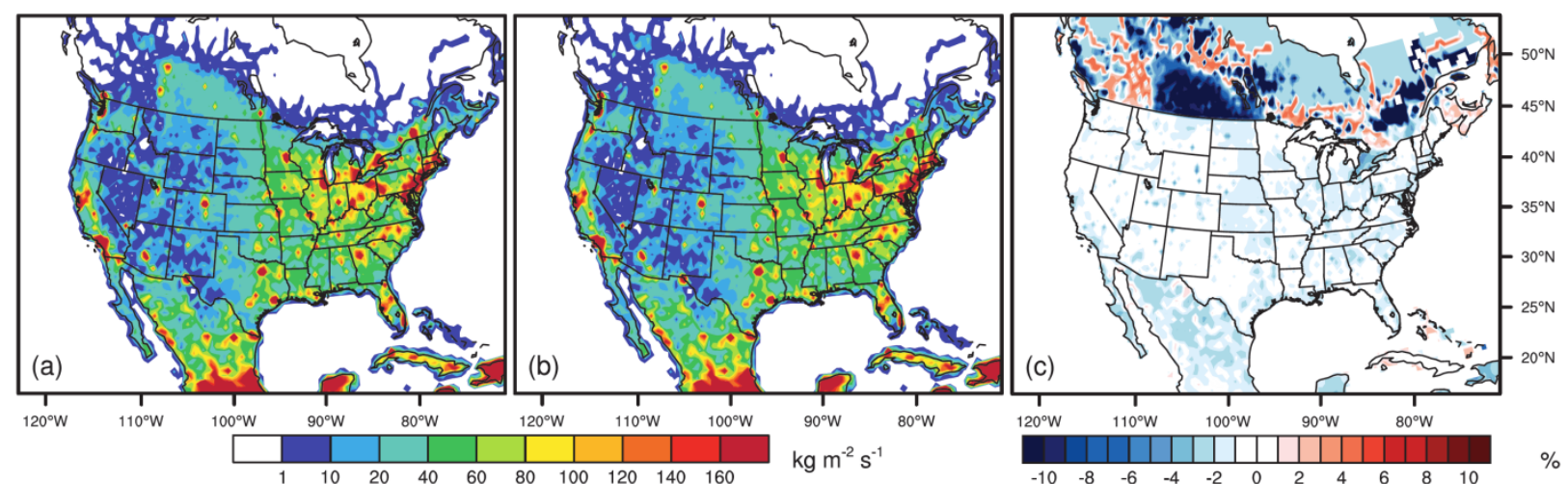

Figure S7. Same as Fig. S4 but for CO.
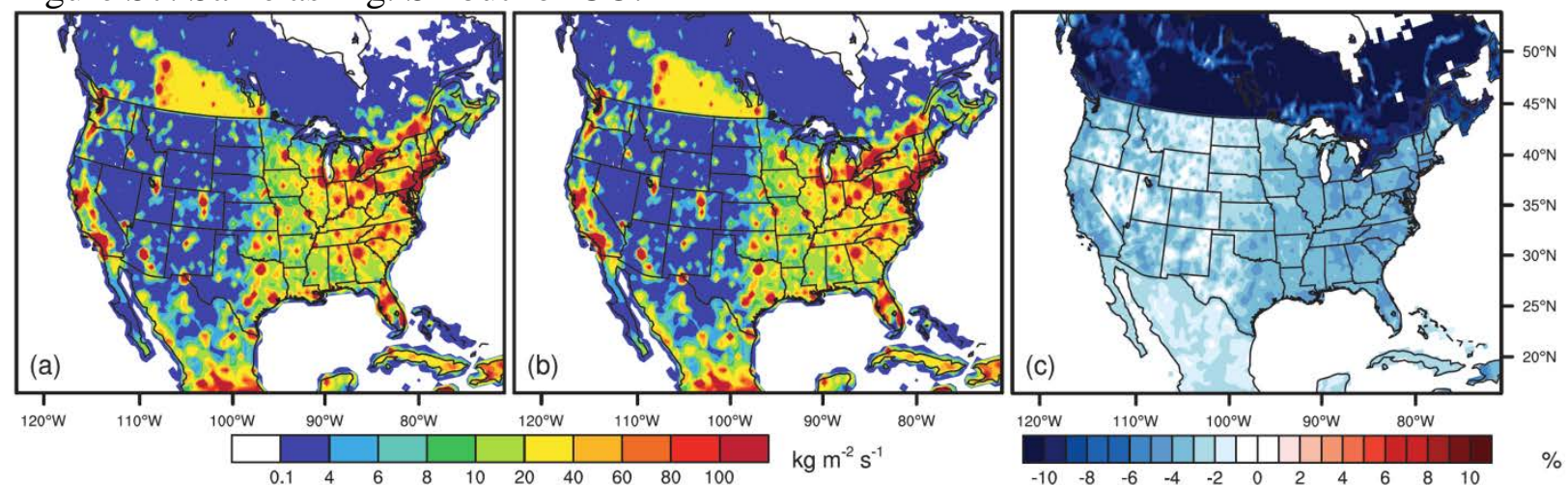

Figure S8. Same as Fig. S4 but for NMVOCs.
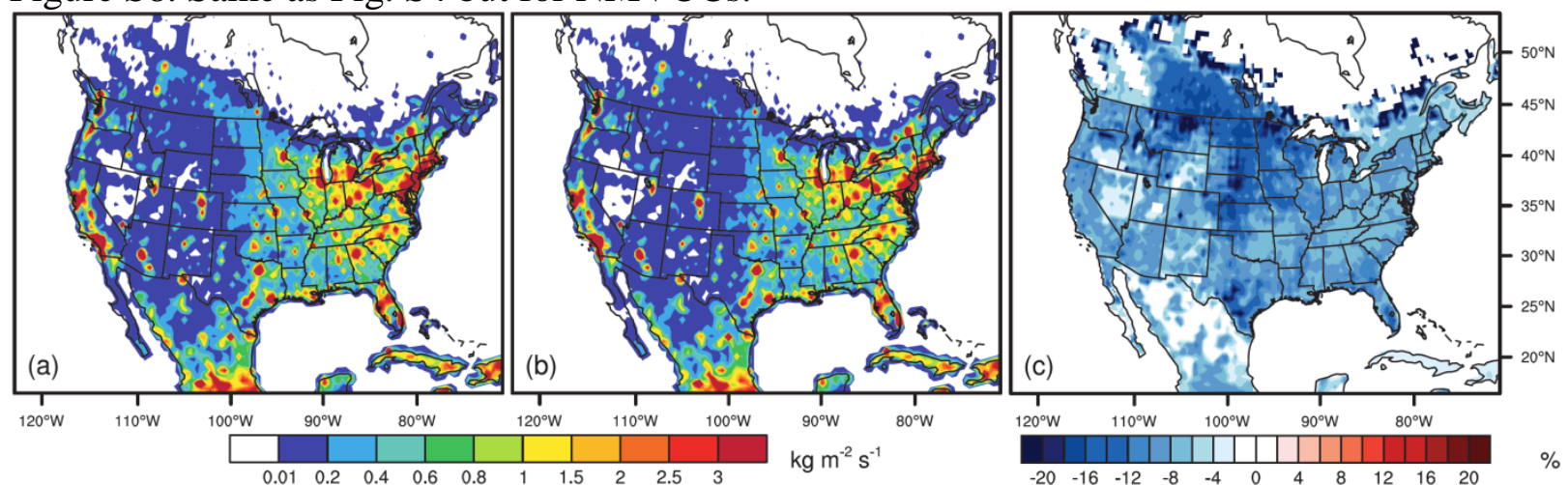

Figure S9. Same as Fig. S4 but for EC.
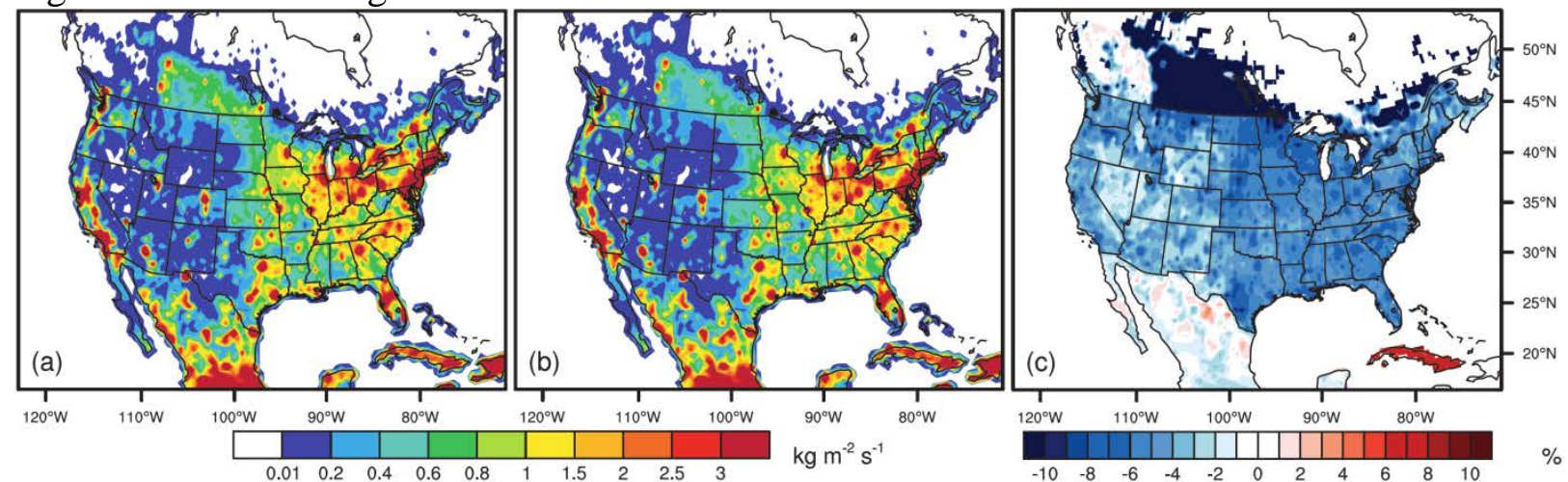

Figure S10. Same as Fig. S4 but for OC. 

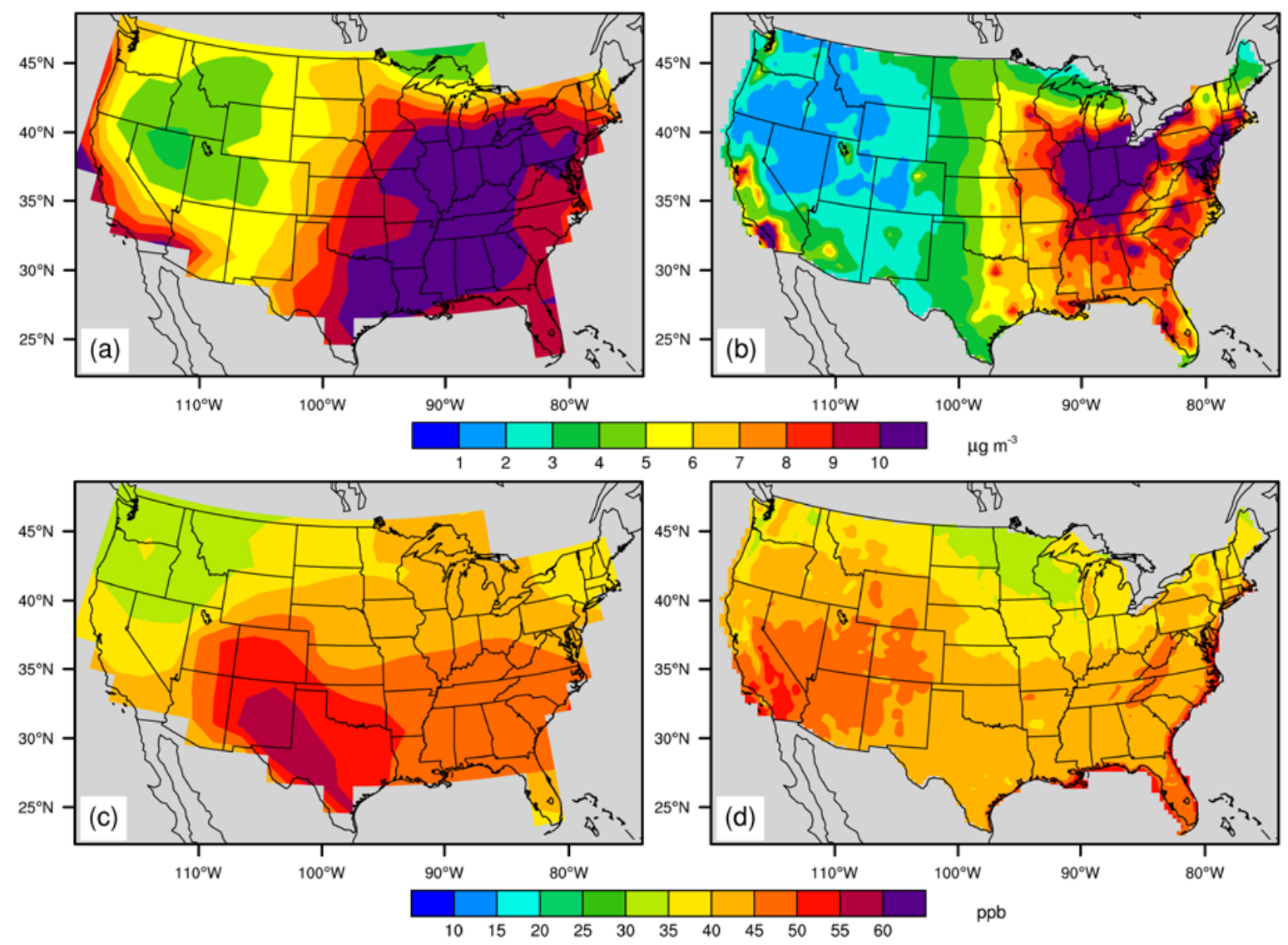

Figure S11. Comparisons for the simulated annual $\mathrm{PM}_{2.5}(\mathrm{a}, \mathrm{b})$ and $\mathrm{O}_{3}$ (c, d) in 2000 (both are for three-year average) between MZ-4 (a, c) and CMAQ (b, d). 

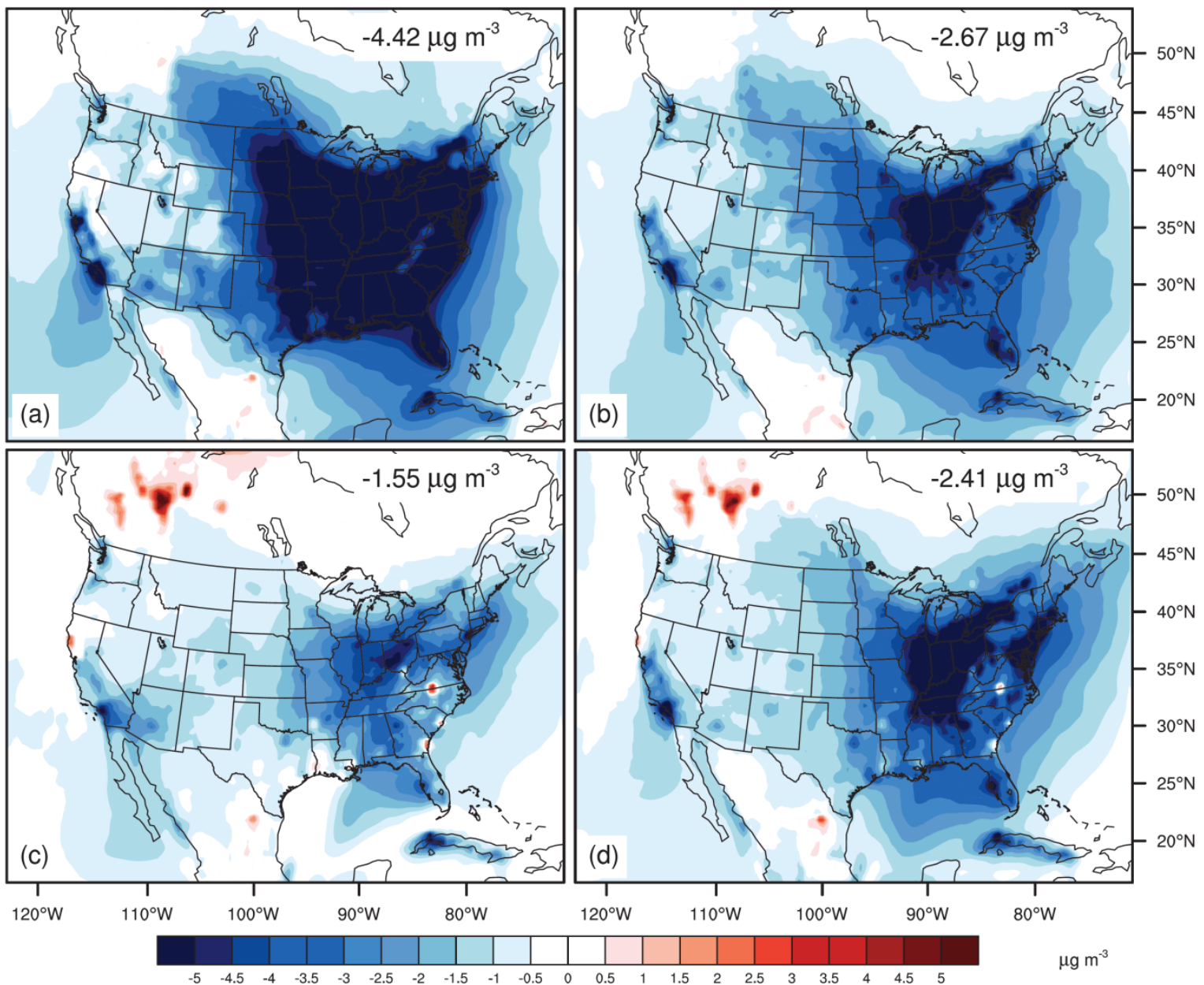

Figure S12. Seasonal distributions of $\mathrm{PM}_{2.5}$ changes $\left(\mu \mathrm{g} \mathrm{m}^{-3}\right)$ between S_REF in 2050 and S_2000 for (a) winter, (b) spring, (c) summer and (d) fall. The three-year annual average over the U.S. is $-2.76 \mu \mathrm{g} \mathrm{m}^{-3}$. 

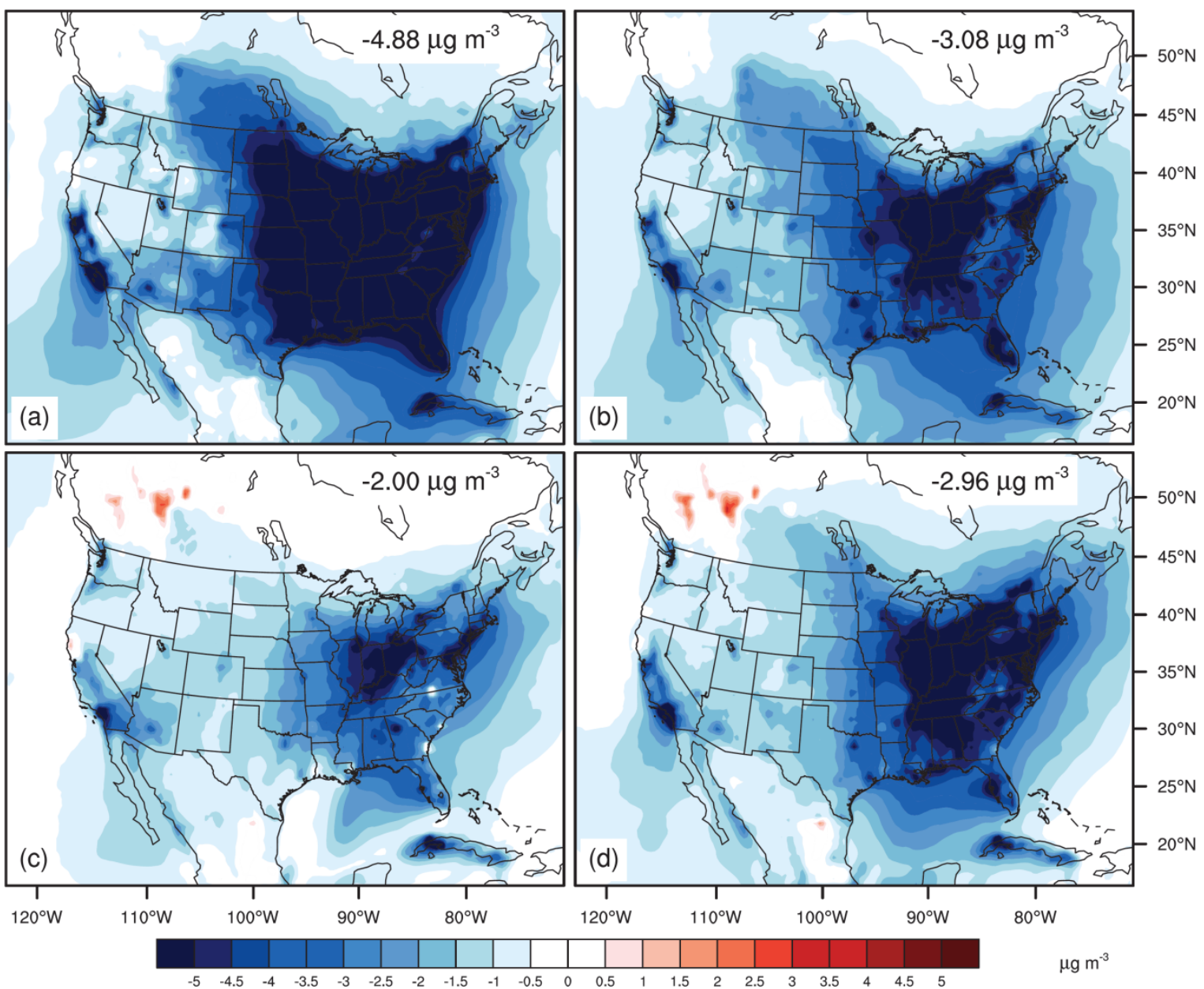

Figure S13. As Fig. S12 but for the changes between S_RCP45 in 2050 and S_2000. The U.S. three-year average is $-3.23 \mu \mathrm{g} \mathrm{m}^{-3}$. 

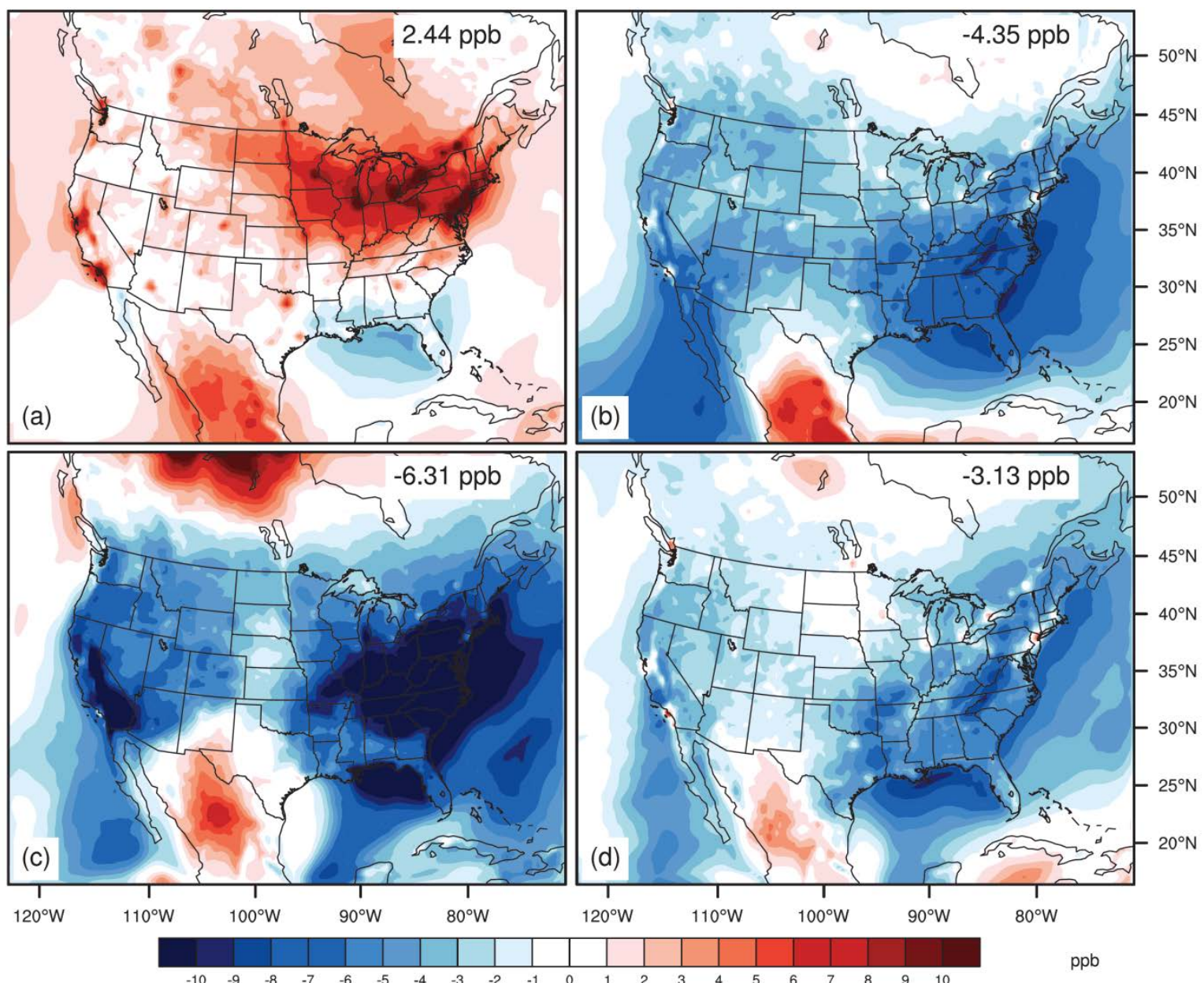

Figure S14. Seasonal distributions of $\mathrm{O}_{3}$ changes (ppb) between S_REF in 2050 and S_2000 for (a) winter, (b) spring, (c) summer and (d) fall. The three-year annual average over the U.S. is $2.84 \mathrm{ppb}$. 

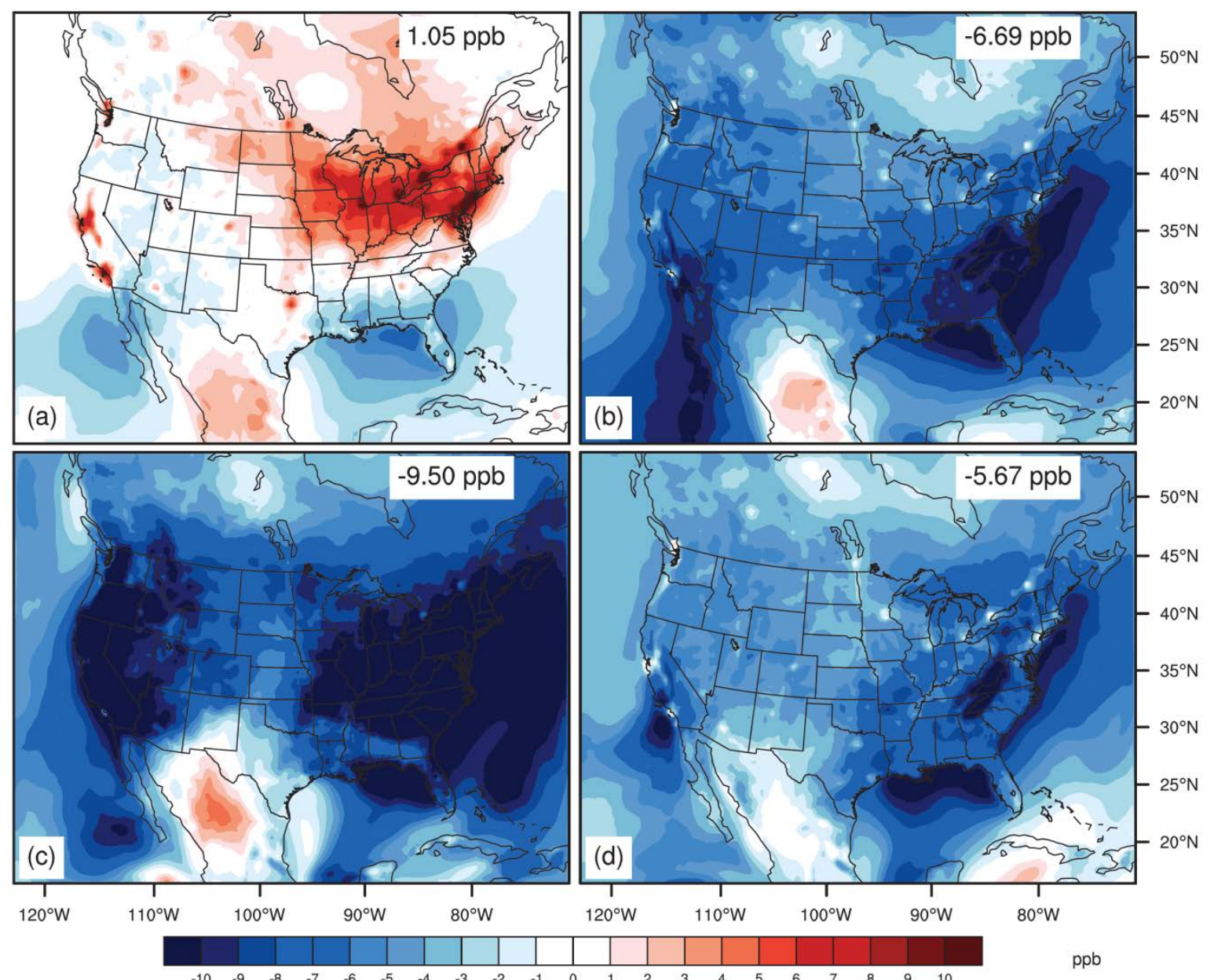

Figure S15. As for Fig. S14, but for the changes between S_RCP45 in 2050 and S_2000. The three-year U.S. average is $-5.20 \mathrm{ppb}$. 

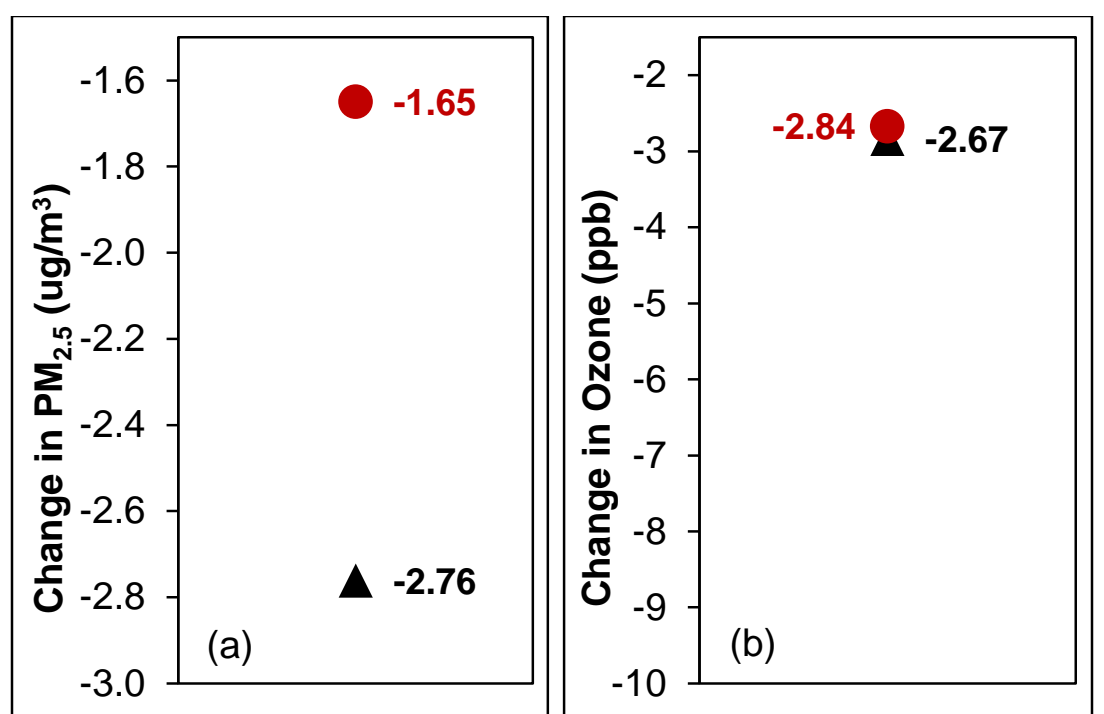

Figure S16. Comparison of air quality changes over the U.S. for REF in 2050 relative to 2000, for this study (black triangle), and MZ4 from WEST2013 (red circle), for (a) the annual average $\mathrm{PM}_{2.5}$, and (b) annual average $\mathrm{O}_{3}$ surface concentration. Values shown are the average of three years for both CMAQ and MZ4. 


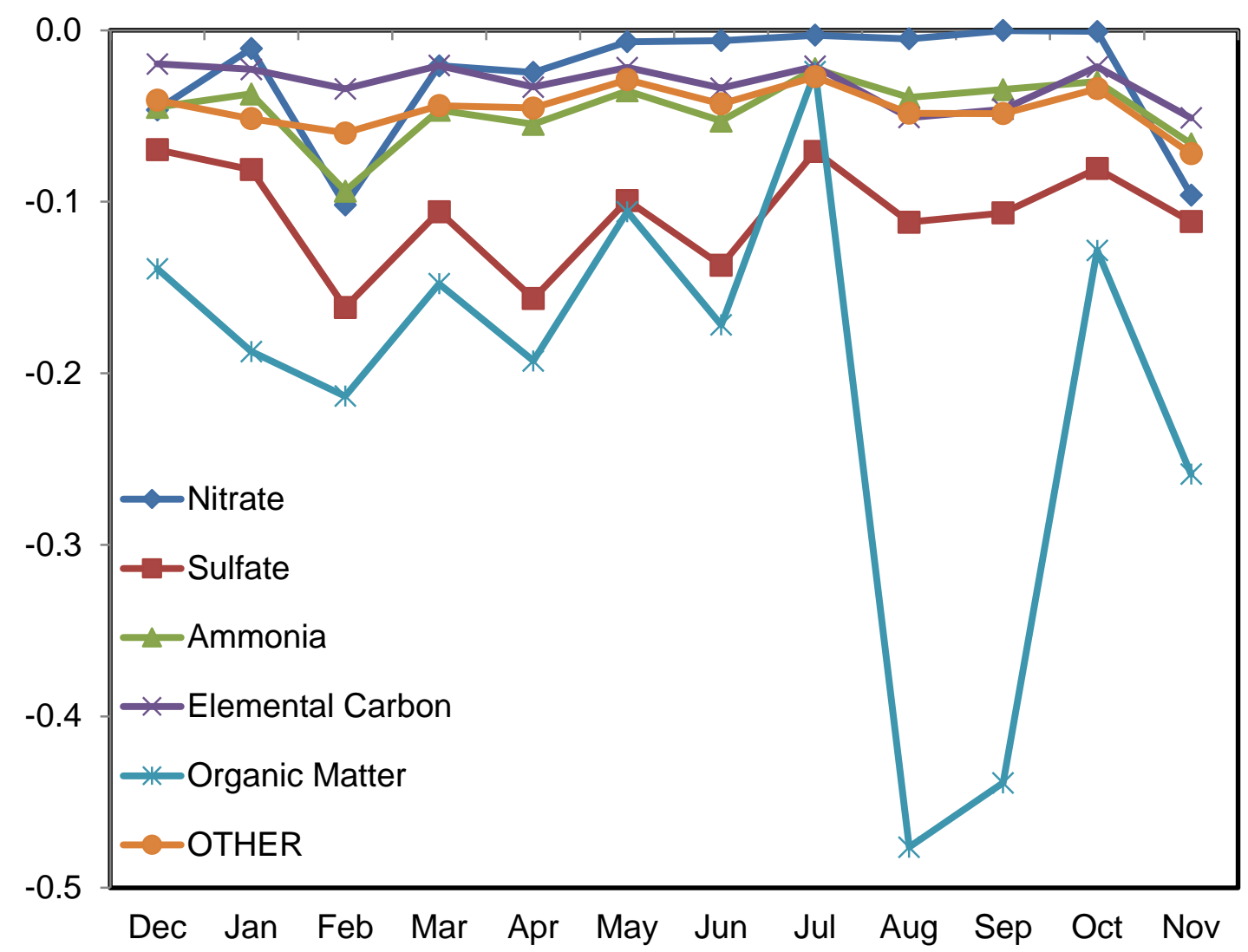

Figure S17. Seasonal distributions of total co-benefits for major $\mathrm{PM}_{2.5}$ components $\left(\mu \mathrm{g} \mathrm{m}^{-3}\right)$. 


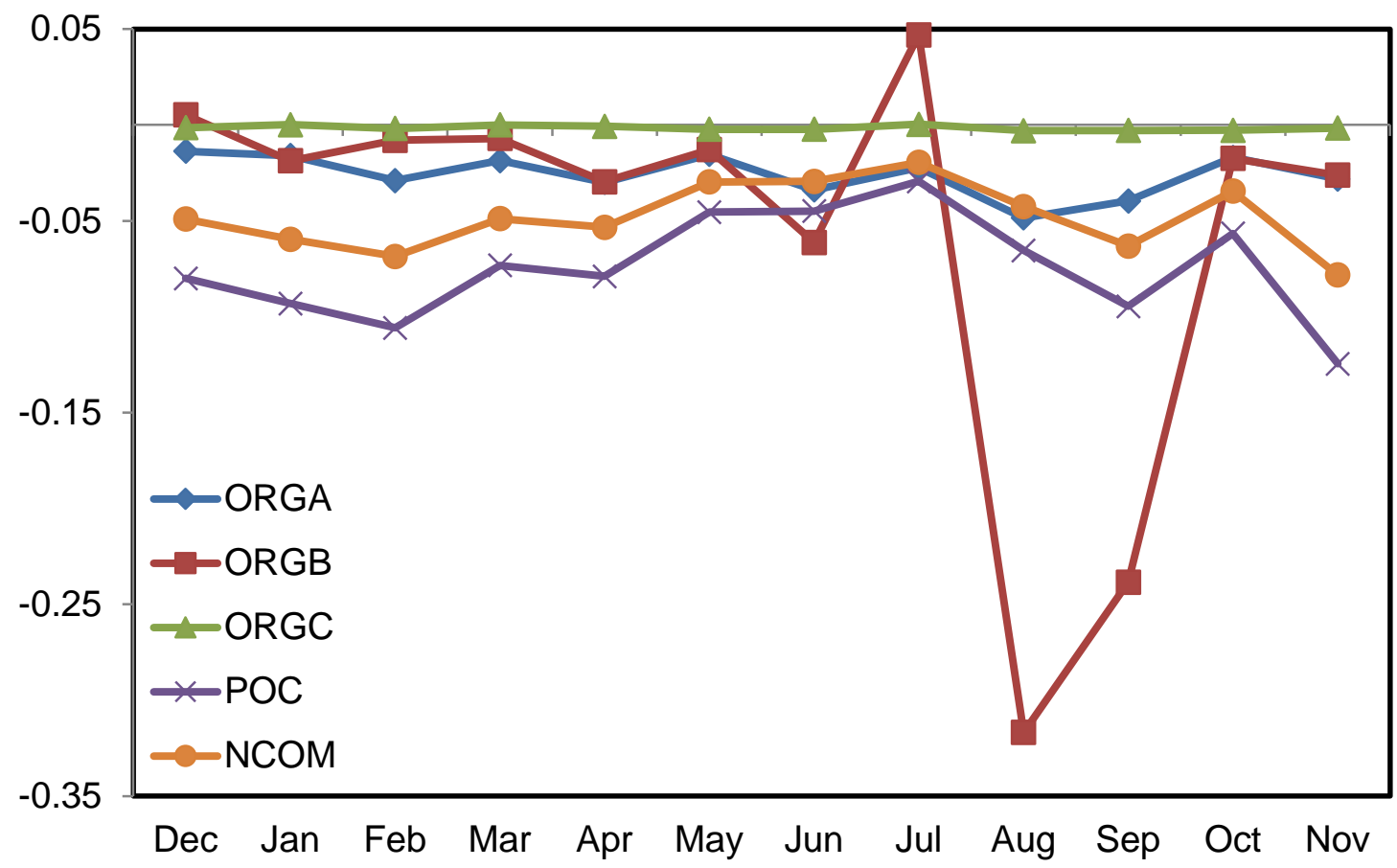

Figure S18. Seasonal distributions of total co-benefits for organic matter $\left(\mathrm{OM}, \mu \mathrm{g} \mathrm{m}^{-3}\right)$, including SOA from anthropogenic source (ORGA), SOA from biogenic source (ORGB), SOA from aqueous-phase oxidation (ORGC), Primary organic carbon (POC) and non-carbon organic matter (NCOM). 


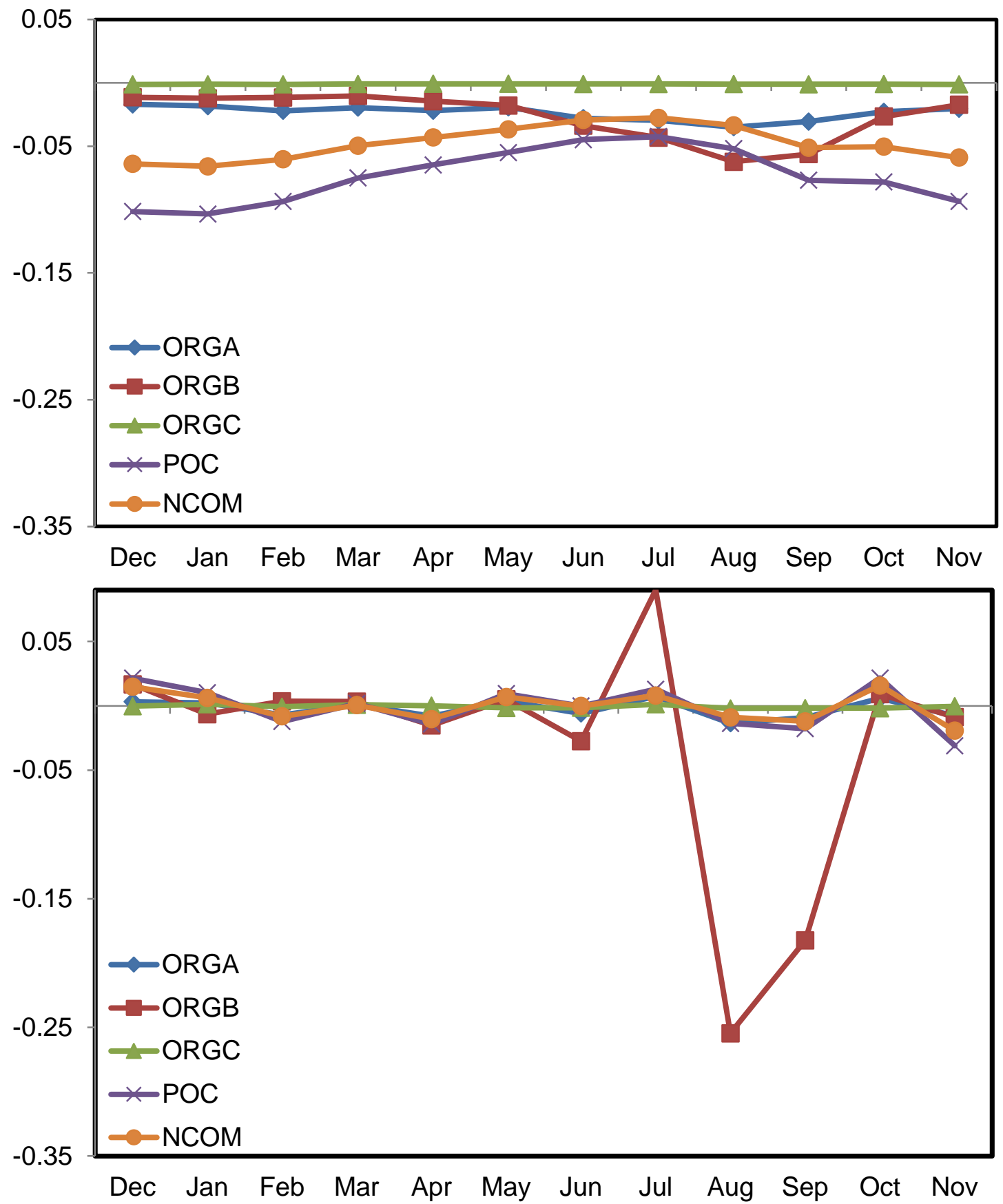

Figure S19. Monthly mean emission co-benefits (top) versus climate co-benefits (bottom) for organic matter (OM, $\mu \mathrm{g} \mathrm{m}^{-3}$ ), including SOA from anthropogenic source (ORGA), SOA from biogenic source (ORGB), SOA from aqueous-phase oxidation (ORGC), Primary organic carbon (POC) and non-carbon organic matter (NCOM). 


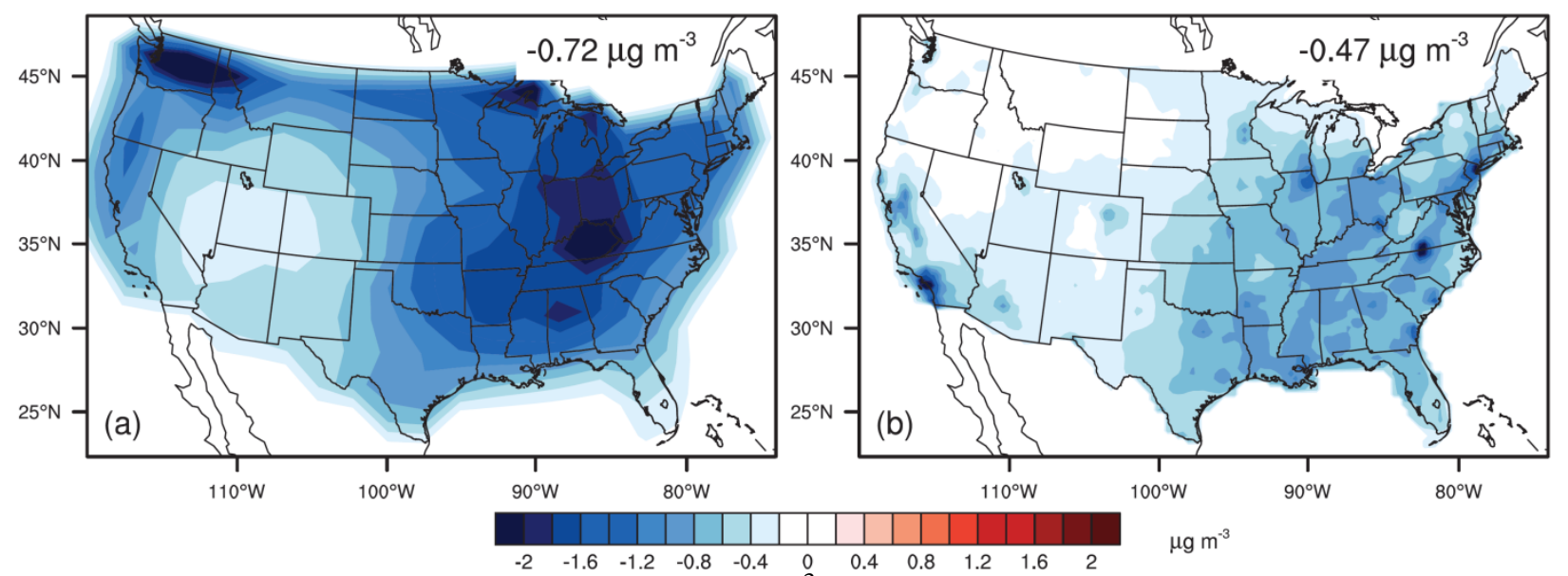

Figure S20. The total co-benefits for $\mathrm{PM}_{2.5}\left(\mu \mathrm{g} \mathrm{m}^{-3}\right)$ in (a) WEST2013 and (b) this study. Both the results from WEST2013 and this study are using three-year averages.

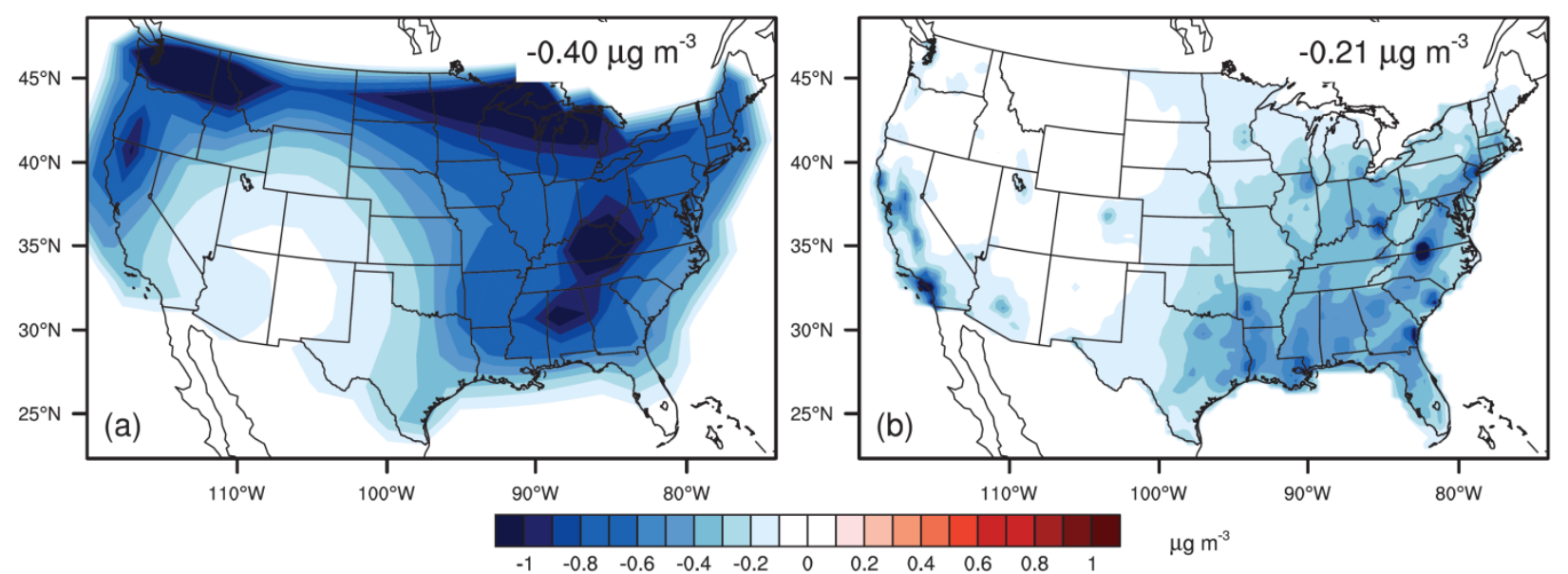

Figure S21. As for Fig. S20 but for OM ( $\mu \mathrm{g} \mathrm{m}^{-3}$, including primary OC, SOA and NCOM).

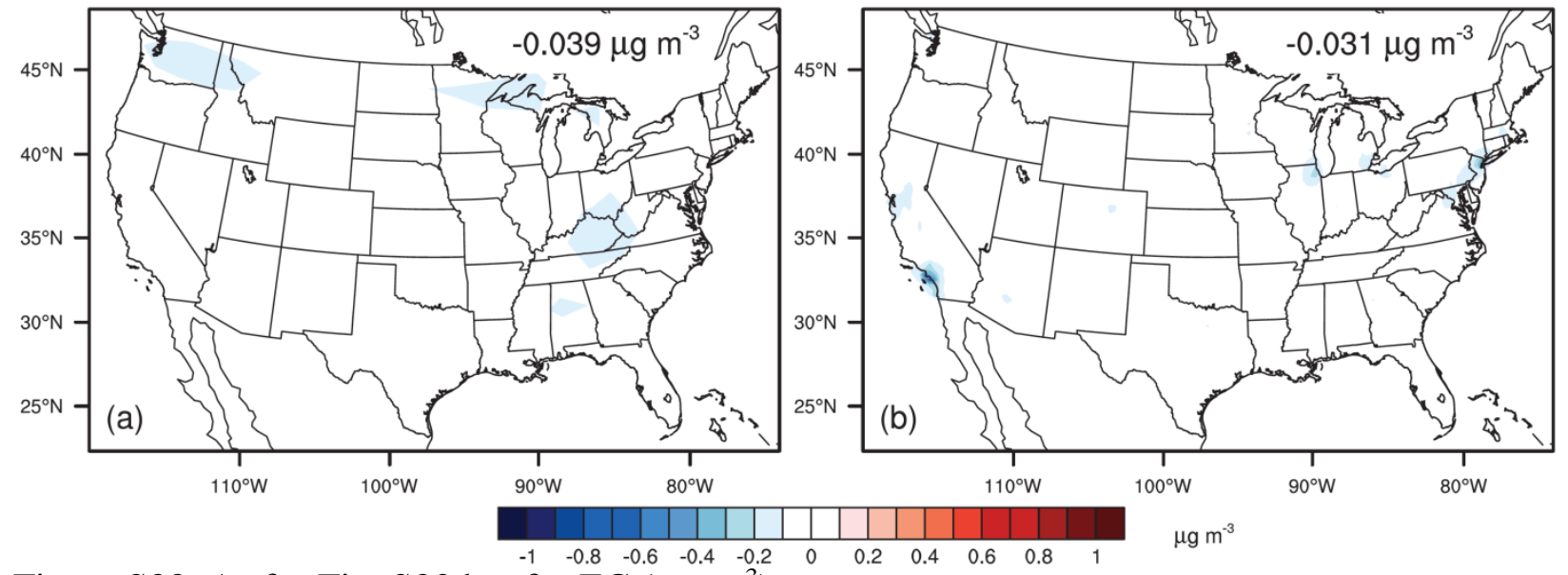

Figure S22. As for Fig. S20 but for EC $\left(\mu \mathrm{g} \mathrm{m}^{-3}\right)$. 


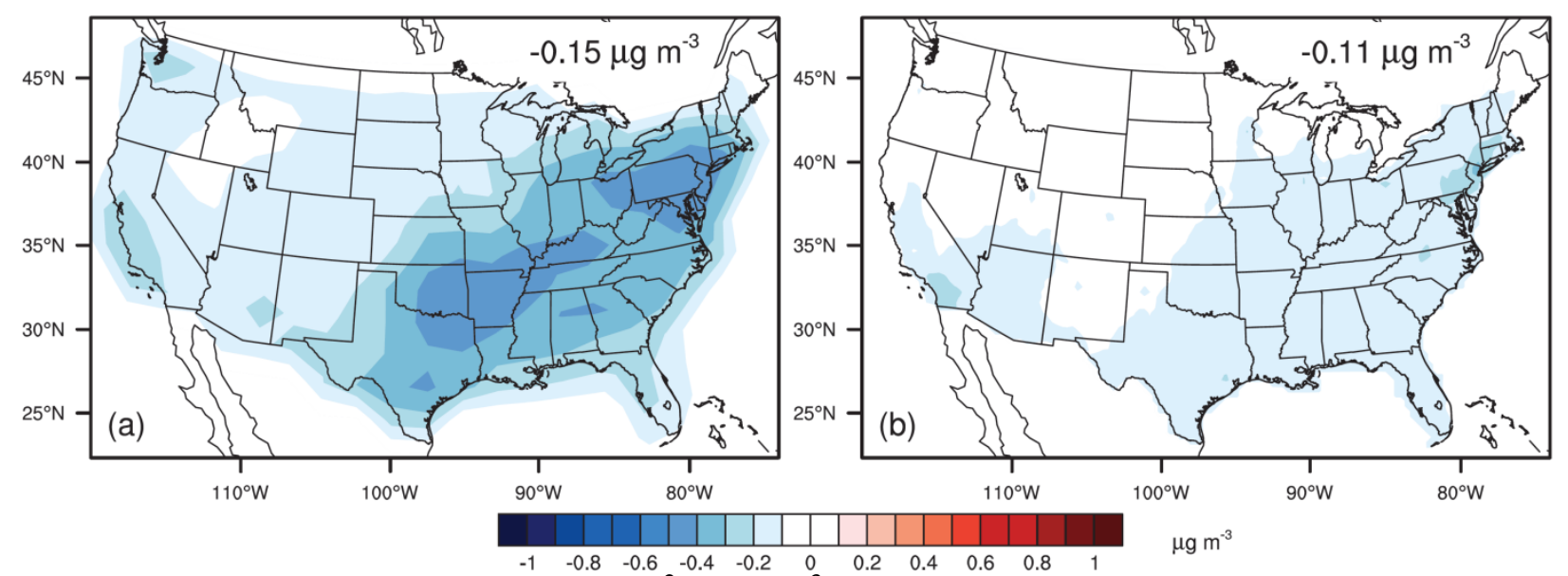

Figure 23. As for Figure S20 but for $\mathrm{SO}_{4}^{2-}\left(\mu \mathrm{g} \mathrm{m}^{-3}\right)$.

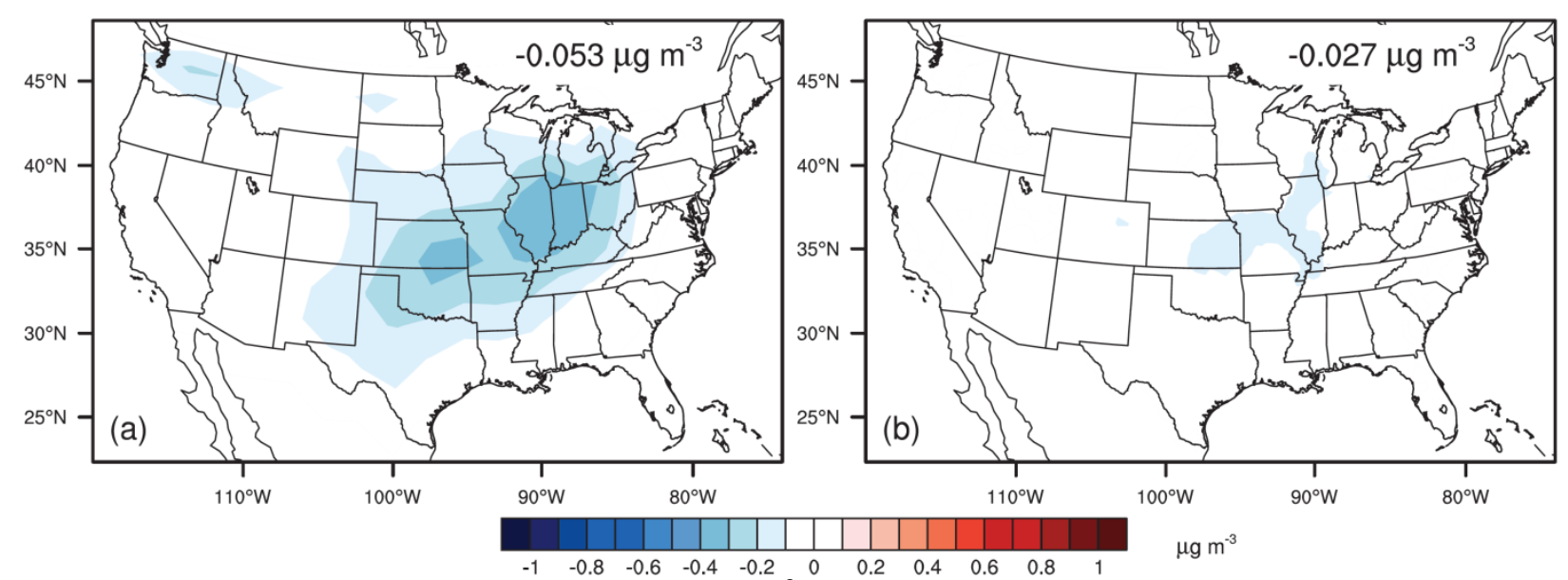

Figure S24. As for Fig. S20 but for $\mathrm{NO}_{3}^{-}\left(\mu \mathrm{g} \mathrm{m}^{-3}\right)$.

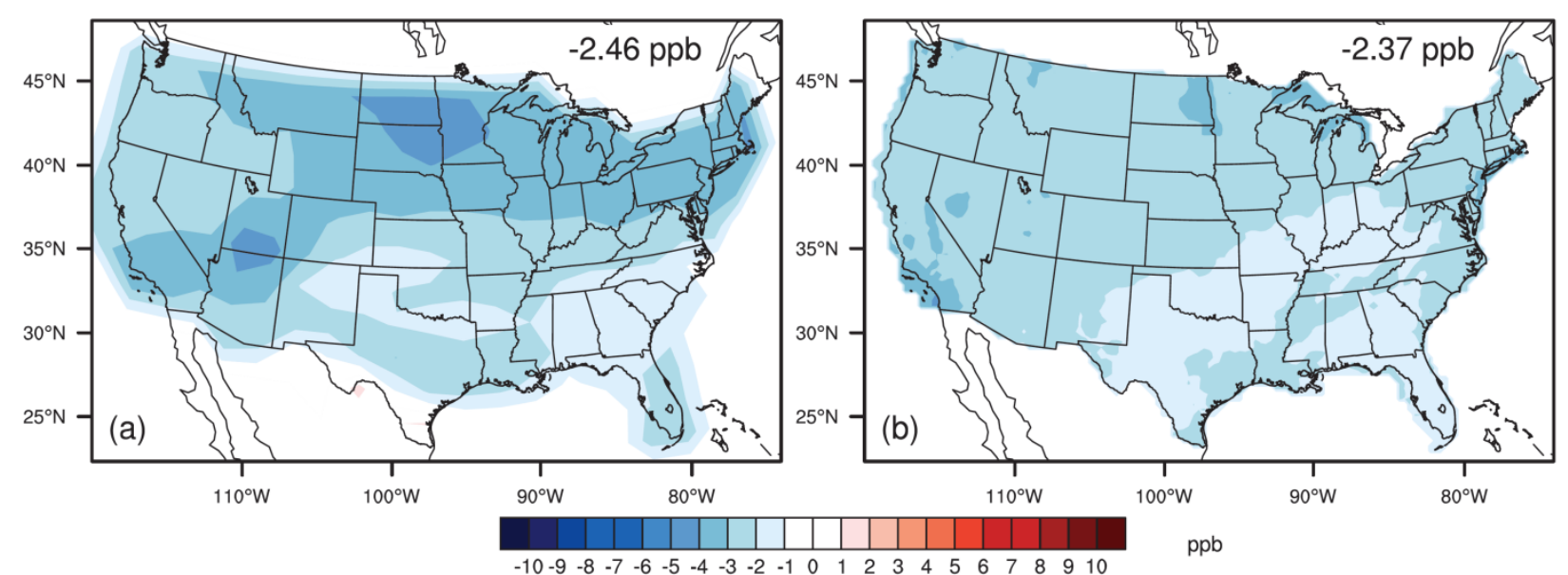

Figure S25. The total co-benefits for annual area-weighted $\mathrm{O}_{3}$ (ppb) in (a) WEST2013 and (b) this study. Both WEST2013 and this study are using three-year averages. 


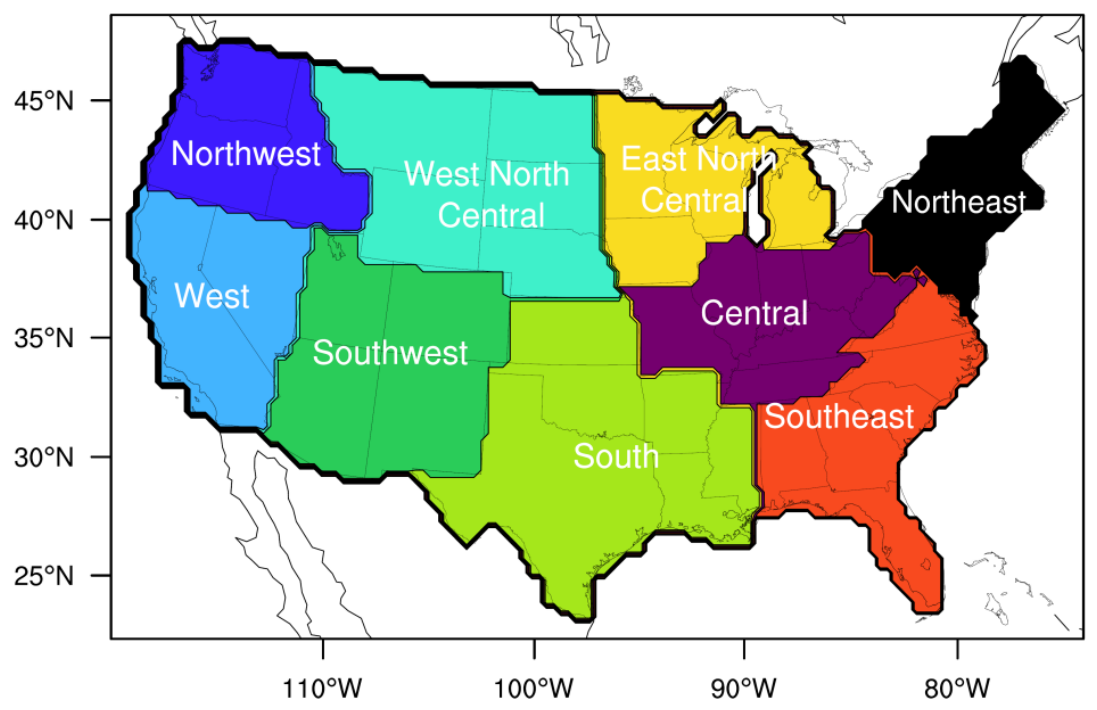

Figure S26. The nine U.S. climate regions defined by the National Oceanic and Atmospheric Administration (http://www.ncdc.noaa.gov/monitoring-references/maps/us-climate-regions.php, accessed 5 December 2014). 